\title{
Pneumatosis coli after Thalidomide Treatment
}

\author{
Toshimitsu Ueki, ${ }^{a}$ Kazuteru Ohashi, ${ }^{a}$ Hiroshi Matsumoto, ${ }^{\mathrm{b}}$ Hiroshi Nakajima, ${ }^{\mathrm{c}}$ \\ Hideki Akiyama ${ }^{a}$, Hisashi Sakamaki ${ }^{a}$ \\ Divisions of ${ }^{a}$ Hematology, ${ }^{b}$ Surgery, and ${ }^{c}$ Gastroenterology, Tokyo Metropolitan Cancer and Infectious Diseases Center, \\ Komagome Hospital, Tokyo, Japan
}

Received March 10, 2006; received in revised form March 28, 2006; accepted April 4, 2006

Int J Hematol. 2006;83:469. doi: 10.1532/IJH97.06059

(C)2006 The Japanese Society of Hematology

Accumulated clinical experience has now provided clear and convincing evidence that thalidomide, alone or in combination, is efficacious in all stages of multiple myeloma (MM) [1,2]. However, thalidomide causes several adverse effects including constipation, which is one of the major adverse effects and may be observed in nearly all patients with increased doses of thalidomide [3]. Here, we report a case of Pneumatosis coli (PC), which was possibly induced by severe constipation due to thalidomide treatment for advanced MM. A 64-year-old man with a history of paraplegia due to a spinal cord compressing plasmacytoma received a fixed dose of thalidomide at $100 \mathrm{mg}$ /day for palliative treatment of the conventional chemotherapy-resistant immunoglobulin A MM. However, after one week of oral administration of this low dose of thalidomide, the patient started to use a laxative and enema to relieve constipation. Three weeks later, the patient developed vomiting and severe abdominal distention, and subsequent abdominal x-ray and computed tomography disclosed a marked gas accumulation in a linear form in the submucosa or subserosa of the entire colon wall (Figure 1), which was consistent with the diagnosis of PC. Colostomy following the abrupt discontinuation of thalidomide resulted in a complete resolution of symptoms and $\mathrm{x}$-ray findings. Although PC usually runs a benign course [4], the symptoms were somehow much more aggressive in our case. A marked accumulation of gas was detected not only within the colon wall but also in the small intestine. PC is still a poorly understood phenomenon and is currently considered to result from primary mucosal insult from varying causes [5]. In our case, constipation probably played a crucial role, and, in addition, decreased colonic motility due to previous spinal cord injury might have been an underlying

Correspondence and reprint requests: Kazuteru Ohashi, MD, FACP, Hematology Division, Tokyo Metropolitan Cancer and Infectious Diseases Center, Komagome Hospital, 3-18-22 Honkomagome Bunkyo-ku, Tokyo 113-8677, Japan; 81-3-38232101; fax: 81-3-3824-1552 (e-mail: k.ohashi@cick.jp). problem. Thus, PC could be one of the potential complications that occur after thalidomide treatment.

\section{References}

1. Morgan GJ, Davies FE. Evolving treatment strategies for myeloma. Br J Cancer. 2005;92:217-221.

2. Rajkumar SV, Kyle RA. Multiple myeloma: diagnosis and treatment. Mayo Clin Proc. 2005;80:1371-1382.

3. Dimopoulos MA, Eleutherakis-Papaiakovou V. Adverse effects of thalidomide administration in patients with neoplastic diseases. Am J Med. 2004;117;508-515.

4. Rennenberg RJ, Koek GH, Van Hootegem P, Strockbrugger RW. Pneumatosis cystoides intestinalis, four cases of a rare disease. Neth J Med. 2002;60:22-25.

5. Snape J, Hulman G, Reddy PR, Panto PN. Pneumatosis coli: an uncommon but treatable cause of faecal incontinence. Int $J$ Clin Pract. 1998;52:501-503.

A

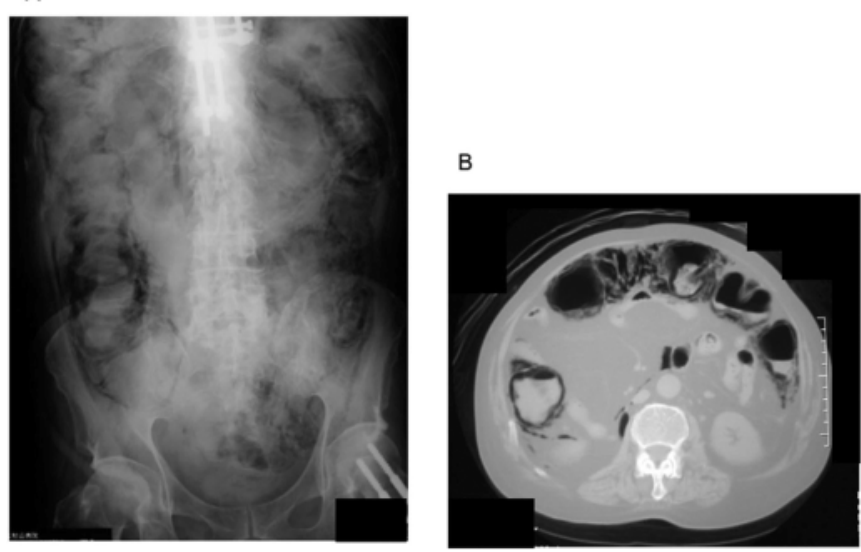

Figure 1. A plain film of the abdomen (A) disclosed a marked gas accumulation in a linear form in the submucosa or subserosa of the entire colon wall, which was suggestive of the presence of pneumatosis coli. A computed tomographic scan (B) revealed air within the wall of the colon. 